\title{
Geospatial approaches to support pelagic conservation planning and adaptive management
}

\author{
L. M. Wedding ${ }^{1, *}$, S. M. Maxwell ${ }^{2,3}$, D. Hyrenbach ${ }^{4}$, D. C. Dunn ${ }^{5}$, J. J. Roberts ${ }^{5}$, \\ D. Briscoe ${ }^{3}$, E. Hines ${ }^{6}$, P. N. Halpin ${ }^{5}$ \\ ${ }^{1}$ Center for Ocean Solutions, Stanford University, Stanford, CA 94305, USA \\ ${ }^{2}$ Department of Biological Sciences, Old Dominion University, 110 Mills Godwin Life Sciences Bldg, Norfolk, VA 23529, USA \\ ${ }^{3}$ Hopkins Marine Station, Stanford University, Pacific Grove, CA 93950, USA \\ ${ }^{4}$ Marine Science Program, Hawai'i Pacific University, Hawai'i Pacific University, 41-202 Kalaniana'ole Hwy., \\ Waimanalo, HI 96795, USA \\ ${ }^{5}$ Marine Geospatial Ecology Lab, Nicholas School of the Environment, Duke University, A324 LSRC, \\ Duke University, Durham, NC 27708, USA \\ ${ }^{6}$ Department of Geography and the Environment, San Francisco State University, 1600 Holloway Ave, \\ San Francisco, CA 94132, USA
}

\begin{abstract}
Place-based management in the open ocean faces unique challenges in delineating boundaries around temporally and spatially dynamic systems that span broad geographic scales and multiple management jurisdictions, especially in the 'high seas'. Geospatial technologies are critical for the successful design of pelagic conservation areas, because they provide information on the spatially and temporally dynamic oceanographic features responsible for driving species distribution and abundance in the open ocean, the movements of protected species, and the spatial patterns of distribution of potential threats. Nevertheless, there are major challenges to implementing these geospatial approaches in the open ocean. This Theme Section seeks to bridge the gap between geospatial science and marine conservation by discussing the use of innovative approaches to support effective marine conservation planning strategies for pelagic ecosystems. We highlight the results of this collection of contributions in 3 main sections: (1) conceptual advances in pelagic conservation; (2) novel information technologies and methodologies; and (3) case studies in the California Current and Pacific Ocean.
\end{abstract}

KEY WORDS: High seas - Pelagic conservation - Marine protected areas - Spatial methods · Dynamic management

\section{INTRODUCTION}

Pelagic ecosystems provide essential habitat for protected species, play a vital role in global climate regulation, support productive fisheries, and represent important ecosystems that require conservation (Hyrenbach et al. 2000, Game et al. 2009). While international conventions call for $10 \%$ of all biomes to be protected by 2020 (Convention on Biological Diversity 2006), only approximately $3.4 \%$ of the global ocean is currently protected within marine pro-

${ }^{*}$ Corresponding author: lwedding@stanford.edu tected areas (MPAs), and just $\sim 0.25 \%$ of open oceans and deep seas beyond national jurisdiction are protected (Toonen et al. 2013, Ban et al. 2014b).

Broad-scale oceanographic spatial datasets from satellites, drifters and tagged animals (e.g. sea surface temperature, thermocline depth and strength, oceanographic fronts) can now be freely and easily accessed online, and, when used in species distribution models as proxies in locations with sparse data, provide an interim alternative to in situ biological assessments (Shaffer \& Costa 2006, Kappes et al.

(C) The authors 2016. Open Access under Creative Commons by Attribution Licence. Use, distribution and reproduction are unrestricted. Authors and original publication must be credited. Publisher: Inter-Research · www.int-res.com 
2010, Block et al. 2011, Suryan et al. 2012). Further, the use of large comprehensive biogeographic and environmental databases, such as AquaMaps (Ready et al. 2010), the Ocean Biogeographic Information System (OBIS) (Grassle et al. 2000, Halpin et al. 2009), and worldwide atlases of physical and biological ocean data (Le Traon et al. 2009, Roemmich et al. 2009) has recently provided a global data center to better understand species-environment relationships and to support predictive modeling techniques in dynamic marine environments (Halpin et al. 2006, Best et al. 2007, Williams et al. 2014). These recent advances in pelagic conservation planning, tracking and remote sensing technology have provided the basis for a geospatial approach to conservation of the pelagic zone.

Geospatial technologies allow for the mapping and monitoring of oceanographic processes and the patterns of ocean productivity, species distribution, and biodiversity that they produce in the open ocean (Halpin et al. 2006, Palacios et al. 2006, Block et al. 2011, Williams et al. 2014). Despite recent technological advances, there are major challenges to implementing a geospatial approach in the open ocean in order to capture data that represent the temporally and spatially dynamic nature of this environment (e.g. Webb et al. 2010, Trebilco et al. 2011, Maxwell et al. 2014). As a result, place-based management in the open ocean faces unique challenges in defining boundaries around temporally and spatially dynamic systems that span broad geographic scales and multiple management jurisdictions (Game et al. 2009, Ban et al. 2014a,b). Therefore, it is critical to bridge the gap between geospatial science and marine conservation in order to translate innovative geospatial approaches to support effective marine conservation planning strategies for pelagic ecosystems.

This paper is an introduction to the overall Theme Section and is a result of the July 2012 Society for Conservation Biology (SCB) special session 'Geospatial Approaches to Support Pelagic Conservation Planning and Adaptive Management' meeting held in Oakland, CA, USA. The goals of this special session were to (1) stimulate scientific collaboration and innovation to advance techniques for pelagic marine conservation in the California Current; (2) provide a forum to share recent research (i.e. data, tools, methods, findings) and to identify gaps in spatial information and innovative methodologies for pelagic conservation planning; and (3) synthesize the findings and publish the results of the symposium to support effective pelagic conservation in the California Current and beyond. This special session and discussion panel brought together geospatial scientists and marine conservation biologists to address the gaps in marine spatial information. In addition, the special session considered the development of innovative geospatial methods necessary to support effective marine conservation strategies for pelagic ecosystems, to summarize future research and conservation goals, and to discuss the necessary steps to facilitate achieving those goals.

This Theme Section is divided into 3 main groups of papers. The first group provides several foundational articles that offer conceptual advances in pelagic conservation planning and management, and recommendations for addressing the challenges in pelagic MPA design, monitoring and evaluation. The second group highlights geospatial tools available for spatially explicit management of pelagic systems including a case study to support biodiversity in the high seas. The third group concludes with case study examples that feature geospatial approaches to support pelagic conservation and management focusing on the California Current ecosystem and beyond. Several of these case study articles review the challenges associated with the spatial and temporal scales of dynamic spatial datasets. We highlight the results of this collection of contributions in the following 3 main sections organized in terms of (1) conceptual advances in pelagic conservation; (2) novel information technologies and methodologies; and (3) case studies in the California Current and Pacific Ocean.

\section{CONCEPTUAL ADVANCES IN PELAGIC CONSERVATION}

The first group of papers begins with a study by Maxwell et al. (2014, this Theme Section), who provide a synthesis of lessons learned and recommendations for managers to address challenges when implementing pelagic protected areas. Few largescale, pelagic MPAs have been in existence long enough to codify ideal management strategies; however, Maxwell et al. (2014) bring together a series of recommendations and pragmatic approaches to managing such large-scale, dynamic areas, with a specific focus on cost-effective management techniques, even in limited-budget scenarios. Insight into objective setting in pelagic MPA design is given, and the authors provide a thoughtful discussion of the methods available to support management prioritization. In addition, they synthesize information from literature, interviews with managers and an informed discussion that occurred during the 'Pelagic Ecosys- 
tems and Management of Marine Protected Areas' meeting, part of the Marine Think Tank held at the International Congress for Conservation Biology (Auckland, New Zealand 2011). Maxwell et al. (2014) also discuss issues related to the enforcement of these large, remote areas. They highlight potential new enforcement technologies and provide clear recommendations to support the considerations necessary for a monitoring program (e.g. participatory monitoring) to inform adaptive management. The authors provide case studies to support the consideration of future partnerships and international collaborations necessary to ensure a common vision for successful and integrated pelagic monitoring, enforcement and management across the high seas and exclusive economic zones (EEZ).

The application of protected areas in the terrestrial environment has long preceded their application in marine environments (Sloan 2002), and this lag is influenced by barriers in the transfer of concepts and ideas between terrestrial and marine ecologists, and by the inherent difficulties associated with the mapping and protection of pelagic habitats. The conservation of biodiversity is one of the most common goals in MPA design and the measure of species and habitat diversity in space and time is an integral component of MPA design, monitoring and evaluation. However, it is unclear whether the 'biodiversity hotspot' concept is always applicable to marine systems. Briscoe et al. (2016, this Theme Section) considered the application of terrestrial conservation principles of hotspot identification to marine systems and provide a clear framework to support hotspot mapping in the open ocean. The ocean is more vast, dynamic and 3-dimensional than the terrestrial landscape (Hyrenbach et al. 2000, Maxwell et al. 2015). As a result, the application of terrestrial conservation hotspot mapping approaches in the pelagic environment has a number of challenges, but also presents a great opportunity to advance our understanding of the patterns and processes in the ocean which are key to supporting pelagic conservation planning. Briscoe et al. (2016) assert that marine conservation biologists must move beyond biodiversity hotspot mapping as a metric for marine conservation planning and focus on trophic productivity hotspots. The authors discuss the temporally persistent, but spatially dynamic nature of the open ocean (e.g. oceanographic fronts), and recommend that trophic productivity hotspots provide a more appropriate metric and proxy for biodiversity in pelagic conservation planning. They provide an important review highlighting the importance of including productivity as a metric for priority setting, the applicabil- ity of large, pelagic MPAs to protecting large-scale productive ocean features and their associated diversity, and the need to transition to more adaptive strategies such as dynamic management and mobile MPAs as technologies continue to advance for determining hotspots across temporally and spatially dynamic marine systems.

\section{NOVEL INFORMATION TECHNOLOGIES AND METHODOLOGIES}

Recent conceptual and technological advances support the information requirements necessary to map and monitor the oceanographic processes that define spatially explicit patterns of ocean productivity, protected species abundance and biodiversity in the open ocean. This section offers a review of the geospatial (ecoinformatic/mapping/analysis) tools designed to support spatial planning and management discussed at our SCB special session. In particular, Marine Geospatial Ecology Tools (MGET) was identified as a useful geospatial tool to support pelagic conservation monitoring and baseline species distribution modeling. MGET is a free, opensource geoprocessing toolbox that can support a variety of marine research, conservation, and spatial planning problems with specific tools relevant for the pelagic environment (Roberts et al. 2010). For instance, this geospatial tool supports (1) accessing and processing oceanographic data from ArcGIS; (2) identifying ecologically relevant oceanographic features in remote sensing imagery; (3) building predictive species distribution models; (4) modeling habitat connectivity by simulating hydrodynamic dispersal of larvae; and (5) detecting spatiotemporal patterns in fisheries and other time series data (Dunn et al. 2008, 2011, Treml et al. 2012).

In addition to geospatial tools, access to and integration of biophysical information is a critical step in the pelagic conservation planning process. Satellite remote sensing has yielded an uninterrupted, readily accessible, global time series of dynamic oceanographic variables spanning decades; these include sea surface temperature (SST) since 1981 (Casey et al. 2010), sea surface wind speed since 1987 (Zhang et al. 2006), sea surface height and ocean currents since 1992 (Woodworth \& Menéndez 2015), and ocean color, chlorophyll concentration, and related biological variables since 1997 and for 1978 to 1986 on a more limited basis (Hu \& Campbell 2013). In recent years, important satellites have exceeded designed mission lifetimes, and nations have launched 
complementary platforms, allowing concurrent observations by multiple orbiters and spurring development of SST and ocean color products that integrate observations from many sensors to reduce data loss due to clouds (e.g. Maritorena et al. 2010, Martin et al. 2012). Large-scale, long-term international initiatives to aggregate in situ observations, implement ocean observing systems, and deploy autonomous mobile platforms continue apace (e.g. Levy et al. 2011, Boyer et al. 2013, Rudnick 2016), yielding new and improved global data products, such as high resolution bathymetries and physiographic classifications (e.g. Yesson et al. 2011, Harris et al. 2014) and maps of oceanographic variables that are currently impossible to observe remotely (e.g. Garcia et al. $2014 a, b)$. By integrating satellite and in situ observations into assimilating ocean models, oceanographers can now offer global estimates of physical, chemical, and biological variables at depth (Metzger et al. 2014, Gehlen et al. 2015). Finally, new algorithms allow automated identification of ecologically relevant dynamic oceanographic features, such as fronts, eddies, and Lagrangian coherent structures (Kai et al. 2009, Chelton et al. 2011, Belkin \& Helber 2015, Haller 2015).

Pelagic conservation measures are often focused on protecting upper trophic level species. Accurately describing and predicting habitats is critical to effective planning and conservation; doing so often requires linking oceanographic variables and other mapped habitat data with geospatially referenced species observations. A number of advances have been made in determining upper trophic 'hotspots', particularly as a result of the Census of Marine Life (CoML). The goal of the CoML was to determine the diversity, distribution and abundance of marine life across taxa, habitats and ocean basins (Costello et al. 2010). With the synthesis of the Tagging of Pacific Predators (TOPP) project, a subproject of CoML, one of the largest multi-species tracking datasets was synthesized to show patterns and hotspots in the Northeast Pacific Ocean (Block et al. 2011). The Census of Fishes, also part of CoML, collated existing global knowledge of fishes across habitats, life stages and methodologies for understanding fish ecology and distribution (O'Dor et al. 2012). Furthermore, the OBIS was developed as part of CoML and has become the primary repository for marine species datasets from around the world (Grassle et al. 2000). OBIS and its subprojects, such as OBIS Spatial Ecological Analysis of Megavertebrate Populations (SEAMAP) that focuses specifically on top predator species, have provided incredible insights into the distribu- tion of marine species all over the globe (e.g. Halpin et al. 2006, Grundlingh et al. 2007, Kot et al. 2010, Webb et al. 2010, Vandepitte et al. 2011). Using OBIS-SEAMAP, Fujioka \& Halpin (2014, this Theme Section) provide an example of a spatio-temporal assessment of biodiversity in the high seas (i.e. Sargasso Sea). The authors address challenges related to the temporal assessment of biodiversity in the pelagic environment through this online tool that provides the user with a framework to facilitate dynamic assessments of biodiversity. Best et al. (2012) also applied the online OBIS-SEAMAP geodatabase to create habitat models for pelagic species along the US east coast and Gulf of Mexico.

\section{CASE STUDIES: CALIFORNIA CURRENT AND BEYOND}

The challenges of implementing geospatial management approaches in the pelagic environment can be immense due to the complexity of highly dynamic spatial and temporal datasets. Further, highly mobile pelagic organisms utilize dynamic oceanographic features, and we have limited understanding of the threats to these species across both time and space. The 4 case study articles presented in this section review the application and advancement of habitatbased models for pelagic species. Pereira et al. (2014, this Theme Section) tested 3 predictions of silver hake Merluccius bilinearis distributions and found that this species demonstrated site-dependent patterns of habitat use in the Gulf of Maine, which may be important for its persistence.

Habitat-based models of cetacean density were the focus of the last 3 articles in this Theme Section. Dransfield et al. (2014, this Theme Section) applied habitat models for humpback whale (Megaptera novaeangliae) occurrence within 2 United States National Marine Sanctuaries. The authors' results support the increased understanding of humpback whale habitat preferences, but also provide a thoughtful consideration of the conflict between human uses and cetacean conservation. As predictive modeling in the pelagic environment continues to expand, it will be important to frame these findings in a way that considers and maps the cumulative impacts (see Maxwell et al. 2013) and human activities that may impact pelagic species conservation and management. Dransfield et al. (2014) demonstrated that shipping traffic has decreased in areas of high predicted humpback whale habitat use, but the authors also encourage adaptive management to mit- 
igate ship-strike risk by altering vessel frequency, speed, size and density within and between shipping lanes in the San Francisco Bay area.

Forney et al. (2015, this Theme Section) applied habitat-based density models in the central North Pacific, providing comprehensive consideration of model validation and accuracy. In addition, the authors consider the change in oceanographic data sources as remote sensing has advanced over the years, discussing the implications of evolving satellite technology on model accuracy and uncertainty. The common thread of temporal variability in species distribution modeling is also woven through the Becker et al. (2014, this Theme Section) work and the authors build further on the case studies that focus on habitat-based density models (Becker et al. 2010, 2012a,b). Becker and co-authors modeled cetacean seasonal density along the California Current using temporally dynamic remotely sensed environmental driver data. Becker et al. (2014) eloquently demonstrate the predictive capacity of habitat models to determine cetacean distribution during parts of the year when data are scarce. The seasonal variability captured in most of the predictive models that the authors presented demonstrates the utility and potential for advancing habitat-based models and applying cross-season predictions. In summary, the habitat-based modeling of cetaceans supports the management of human impacts (e.g. vessel traffic, fisheries interactions) and informs the identification of pelagic areas to prioritize for conservation and assist in adaptive management considerations. The case studies featured in this Theme Section highlight the challenges associated with habitat-based modeling across broad geographic areas, under datalimited conditions and in support of conservation of highly mobile species.

\section{EMERGING RESEARCH FRONTIERS}

Continued efforts to map and monitor dynamic oceanographic characteristics and static geomorphic features across space and time will provide a strong foundation to support growing efforts to spatially manage the deep sea and open ocean (Chelton et al. 2011, Belkin \& Helber 2015). Future research directions should focus on addressing the challenges associated with integrating the dynamic oceanographic datasets available through remote sensing (e.g. SST, chlorophyll $\alpha$ ) into products capable of capturing the spatial and temporal variability in the environment, at the scales relevant to pelagic predators and their prey. The oceans are dynamic, spatially complex, multi-dimensional systems, and currently geospatial tools and methods can capture the 3 dimensional complexity in the open ocean, but the temporal component (4th dimension) is a challenge. As more adaptive approaches to management progress under a changing climate (e.g. dynamic ocean management and mobile MPAs; Dunn et al. 2011, Maxwell et al. 2015), it will be critical to support the advancement of geospatial tools that allow for temporally dynamic data visualization and analysis.

Models that explain the shifts in distribution already occurring as a result of climate change are critical to understanding how predictive habitat modeling can be used to produce scenarios of how habitats might shift as climate change continues. Pinsky et al. (2013) showed how climate-induced changes in marine species distribution varied widely over large spatial scales. They attribute the variability they found in response to climate velocities, or 'the rate and direction that climate shifts across the landscape' (Pinsky et al. 2013, p. 1239), to local context rather than species characteristics, which has important implications for using localized data to inform future shifts in habitat. Hazen et al. (2012) use predictive habitat modeling techniques to suggest that with climate change we will see up to a $35 \%$ change in core habitat of a suite of top marine predators, and a general shift northward. Other modeling techniques have shown the impact of climate shifts across entire food chains, including potential impacts on fish biomass and subsequent movements of fishing fleets (Howell et al. 2013). Looking to the future in planning spatial conservation measures is critical as environments, species and humans shift in response to changing conditions.

As remote sensing technologies continue to advance, scientists have the ability to use widely available global biophysical datasets and spatial predictive models to help inform MPA design in dynamic and remote environments. The ability to statistically define habitats and prey aggregations in the absence of data in the pelagic environment is advancing rapidly. These advances involve determining what metrics most accurately define bathymetric and hydrographic habitats (e.g. Suryan et al. 2012, Michael et al. 2014) and what modeling techniques most accurately relate animal distribution to these environmental variables (Wingfield et al. 2011), as well as models that explicitly take energetics, movement and environment into account (Suryan et al. 2006). For example, Pikesley et al. (2013) illustrate the first application of ensemble models for quanti- 
fying the habitat of olive ridley sea turtles Lepidochelys olivacea. This novel approach integrates multiple models into a single powerful prediction (Araújo \& New 2007).

Habitat-based modeling must advance and integrate validation tools into the modeling process. The study of uncertainty (e.g. confusion matrix, sensitivity analysis) and the mapping of uncertainty as a visual assessment tool will be critical to the validation and communication of uncertainty. Further, there is a clear need to focus on bridging the gap between the communication of model uncertainty and the translation of modeling results to policy makers. Pelagic conservation planning processes will aim to encompass metrics of interest, such as diversity or productivity of marine systems. By capturing such metrics, it is implied that ecologically important processes, features or components of the systems will be protected.

One of the key questions brought to the forefront in recent years is whether productivity and diversity are linked and coupled in space and time in marine systems. In terrestrial systems, plants are the main primary producers. Plants are relatively long-lived, stationary in space and time (Tang et al. 2006); thus the widely held paradigm is that increasing productivity results in increased diversity in terrestrial systems as a diversity of upper trophic level species are found in these relatively stationary productivity 'hotspots' (Gaston 2000, Richmond et al. 2007). In contrast, primary production in the ocean is dominated by phytoplankton that move dynamically in space in time, with changing ocean conditions such as currents and upwelling (Levin 1994, Carr et al. 2003, Lourie \& Vincent 2004). Furthermore, the long trophic links between primary producers and upperlevel consumers introduce potential spatio-temporal lags between areas of elevated primary production and localized foraging hotspots for marine predators (e.g. Hyrenbach et al. 2000, Hooker at al. 2011). Thus, a more accurate understanding of the mechanistic links between the productivity and diversity of both planktonic and nektonic organisms is essential to developing comprehensive targets for conservation planning in pelagic ecosystems.

As we transition toward ecosystem-based approaches that fully integrate the biophysical system, social system, economic system and marine governance, we need to embrace the complexity of human relationships with ecosystems in order to develop and implement viable management strategies (Fulton et al. 2011). Although social data are recognized as important for understanding a system (Naidoo et al. 2006, Stephenson \& Mascia 2009), approaches that characterize the human dimensions of marine ecosystems remain fragmented, sectoral, coastal or even land-based, and limited in scope. This may be due largely to disparities in data availability and lack of familiarity with social science research methods among practitioners (Koehn et al. 2013, Kittinger et al. 2014, Le Cornu et al. 2014). Although characterizing social data can be challenging (e.g. Knight et al. 2010), researchers are developing innovative techniques to map human dimensions in ocean environments (e.g. St. Martin 2001, Pittman et al. 2011, Klain \& Chan 2012, see Koehn et al. 2013 for a review). In marine systems, understanding the 3 dimensional spatial distribution of activities can help practitioners optimize spatial plans to maximize benefits among user groups (White et al. 2012). Despite recent advances in the integration of social data into marine spatial planning (Richardson et al. 2006, Klein et al. 2008, Ban \& Klein 2009, Ban et al. 2014b), practical approaches for incorporating human dimensions in marine governance and linking them to biophysical attributes are limited (Dahl et al. 2009). Future research should focus on the dynamic spatial integration of social data with biophysical datasets in the pelagic environment to support conservation planning across a peopled seascape.

\section{CONCLUSION}

The articles in this Theme Section address new directions in pelagic conservation and management, with specific application to the California Current, and more broadly other boundary currents and oceanic habitats. Challenges exist for implementing geospatial management approaches in the pelagic environment, given the lack of comprehensive biophysical and social datasets, the large spatial scales of the oceanic habitat features, and the inherent dynamic nature of the habitats and the distributions of anthropogenic threats and protected species distributions. However, this compilation of articles provides the latest lessons learned to facilitate the successful implementation of comprehensive marine spatial planning of the pelagic environment. In particular, we sought to identify key commonalities (i.e. concepts, knowledge, data, tools) for the design of spatial management measures. Further, several articles in this Theme Section provide recommendations for pelagic MPA design, implementation, or evaluation based on reviews of the current direction of spatial planning for pelagic ecosystems and recent conceptual advances and technological developments. 
Conservation practitioners require syntheses of the lessons learned from recent conservation efforts in pelagic ecosystems around the world, in order to apply these lessons to successfully implement future spatial planning in the marine environment. There is a unique set of economic, logistical, and biophysical challenges that must be considered in these pelagic areas. The dynamic nature of pelagic species and environmental gradients makes the feasibility of spatial management in the pelagic ocean challenging and necessitates the use of geospatial technology. It is our hope that the research presented in this Theme Section will provide key case studies to advance the use of geospatial technologies in support of pelagic conservation in the California Current, and beyond.

Acknowledgements. This synthesis of the July 2012 SCB symposium was published under NOAA Grant \#NA10AO R4170060, California Sea Grant College Program Project \#W12-55PD, through NOAA'S National Sea Grant College Program, US Dept. of Commerce. The statements, findings, conclusions and recommendations are those of the author(s) and do not necessarily reflect the views of California Sea Grant, NOAA or the US Dept. of Commerce.

\section{LITERATURE CITED}

Araújo MB, New M (2007) Ensemble forecasting of species distributions. Trends Ecol Evol 22:42-47

> Ban NC, Klein CJ (2009) Spatial socioeconomic data as a cost in systematic marine conservation planning. Conserv Lett 2:206-215

Ban NC, Bax NJ, Gjerde KM, Devillers R and others (2014a) Systematic conservation planning: a better recipe for managing the high seas for biodiversity conservation and sustainable use. Conserv Lett 7:41-54

> Ban NC, Maxwell SM, Dunn D, Hobday AJ and others (2014b) Better integration of sectoral planning and management approaches for the interlinked ecology of the open oceans. Mar Policy 49:127-136

Becker EA, Forney KA, Ferguson MC, Foley DG, Smith RC, Barlow J, Redfern JV (2010) Comparing California Current cetacean-habitat models developed using in situ and remotely sensed sea surface temperature data. Mar Ecol Prog Ser 413:163-183

Becker EA, Foley DG, Forney KA, Barlow J, Redfern JV, Gentemann CL (2012a) Forecasting cetacean abundance patterns to enhance management decisions. Endang Species Res 16:97-112

Becker EA, Forney KA, Ferguson MC, Barlow J, Redfern JV (2012b) Predictive modeling of cetacean densitites in the California Current ecosystem based on summer/fall ship surveys in 1991-2008. NOAA, La Jolla, CA

Becker EA, Forney KA, Foley DG, Smith RC, Moore TJ, Barlow J (2014) Predicting seasonal density patterns of California cetaceans based on habitat models. Endang Species Res 23:1-22

Belkin IM, Helber RW (2015) Physical oceanography of fronts: an editorial. Deep-Sea Res II 119:1-2
Best BD, Halpin PN, Fujioka E, Read AJ, Qian SS, Hazen LJ, Schick RS (2007) Geospatial web services within a scientific workflow: predicting marine mammal habitats in a dynamic environment. Ecol Inform 2:210-223

> Best BD, Halpin PN, Read AJ, Fujioka E and others (2012) Online cetacean habitat modeling system for the US east coast and Gulf of Mexico. Endang Species Res 18:1-15

Block BA, Jonsen ID, Jorgensen SJ, Winship AJ and others (2011) Tracking apex marine predator movements in a dynamic ocean. Nature 475:86-90

Boyer TP, Antonov JI, Baranova OK, Coleman C and others (2013) World Ocean Database 2013. In: Levitus S, Mishonov A (eds) NOAA Atlas NESDIS 72. National Oceanographic Data Center, Ocean Climate Laboratory, Silver Spring, MD. http://docs.lib.noaa.gov/noaa_documents/ NESDIS/NODC/NOAA_Atlas_NESDIS/NOAA_Atlas_ NESDIS_72.pdf

Briscoe DK, Maxwell SM, Kudela R, Crowder LB, Croll D (2016) Are we missing important areas in pelagic marine conservation? Redefining conservation hotspots in the ocean. Endang Species Res 29:229-237

Carr MH, Neigel JE, Estes JA, Andelman S, Warner RR, Largier JL (2003) Comparing marine and terrestrial ecosystems: implications for the design of coastal marine reserves. Ecol Appl 13:90-107

Casey KS, Brandon TB, Cornillon P, Evans R (2010) The past present, and future of the AVHRR pathfinder SST programm. In: Barale V, Gower JFR, Alberotanza L (eds) Oceanography from space. Springer, Dordrecht, p 273-287

Chelton DB, Schlax MG, Samelson RM (2011) Global observations of nonlinear mesoscale eddies. Prog Oceanogr 91:167-216

Convention on Biological Diversity (2006) Review of implementation of the programme of work on protected areas for the period 2004-2006. 8th Ordinary Meeting of the Conference of the Parties to the Convention on Biological Diversity, 20-31 March 2006, Curitiba, Brazil. Secretariat of the Convention on Biological Diversity, Montreal

Costello MJ, Coll M, Danovaro R, Halpin P, Ojaveer H, Miloslavich P (2010) A census of marine biodiversity knowledge, resources, and future challenges. PLoS ONE 5:e12110

Dahl R, Ehler C, Douvere F (2009) Marine spatial planning, a step-by-step approach toward ecosystem-based management.. IOC Manual and Guides No. 53, ICAM Dossier No. 6. UNESCO, Paris

> Dransfield A, Hines E, McGowan J, Holzman B and others (2014) Where the whales are: using habitat modeling to support changes in shipping regulations within National Marine Sanctuaries in Central California. Endang Species Res 26:39-57

> Dunn DC, Kot CY, Halpin PN (2008) A comparison of methods to spatially represent pelagic longline fishing effort in catch and bycatch studies. Fish Res 92:268-276

> Dunn DC, Boustany AM, Halpin PN (2011) Spatio-temporal management of fisheries to reduce by-catch and increase fishing selectivity. Fish Fish 12:110-119

Forney KA, Becker EA, Foley DG, Barlow J, Oleson EM (2015) Habitat-based models of cetacean density and distribution in the central North Pacific. Endang Species Res 27:1-20

> Fujioka E, Halpin PN (2014) Spatio-temporal assessments of biodiversity in the high seas. Endang Species Res 24: $181-190$ 
Fulton EA, Smith AD, Smith DC, van Putten IE (2011) Human behavior: the key source of uncertainty in fisheries management. Fish Fish 12:2-17

Game ET, Grantham HS, Hobday AJ, Pressey RL and others (2009) Pelagic protected areas: the missing dimension in ocean conservation. Trends Ecol Evol 24:360-369

Garcia HE, Locarnini RA, Boyer TP, Antonov JI and others (2014a) World Ocean Database 2013, Vol 3: Dissolved oxygen, apparent oxygen utilization, and oxygen saturation. In: Levitus S, Mishonov A (eds) NOAA Atlas NESDIS 75. National Oceanographic Data Center, Ocean Climate Laboratory, Silver Spring, MD. http://docs.lib.noaa.gov/ noaa_documents/NESDIS/NODC/NOAA_Atlas_NESDIS/ NOAA_Atlas_NESDIS_72.pdf

Garcia HE, Locarnini RA, Boyer TP, Antonov JI and others (2014b) World Ocean Database 2013, Vol 4: Dissolved inorganic nutrients (phosphate, nitrate, silicate). In: Levitus S, Mishonov A (eds) NOAA Atlas NESDIS 76. National Oceanographic Data Center, Ocean Climate Laboratory, Silver Spring, MD. http://docs.lib.noaa.gov/noaa documents/NESDIS/NODC/NOAA_Atlas_NESDIS/NOAA _Atlas_NESDIS_72.pdf

> Gaston KJ (2000) Global patterns in biodiversity. Nature 405:220-227

Gehlen M, Barciela R, Bertino L, Brasseur P and others (2015) Building the capacity for forecasting marine biogeochemistry and ecosystems: recent advances and future developments. J Op Oceanogr 8:S168-S187

Grassle JF (2000) The Ocean Biogeographic Information System (OBIS): an on-line, worldwide atlas for accessing, modeling and mapping marine biological data in a multidimensional geographic context. Oceanography 13:5-7

Grundlingh ML, St Ange UBV, Bolton JJ, Bursey M and others (2007) AfrOBIS: a marine biogeographic information system for sub-Saharan Africa. S Afr J Sci 103:91-93

> Haller G (2015) Lagrangian coherent structures. Annu Rev Fluid Mech 47:137-162.

> Halpin PN, Read AJ, Best BD, Hyrenbach KD and others (2006) OBIS_SEAMAP: developing a biogeographic research data commons for the ecological studies of marine mammals, seabirds, and sea turtles. Mar Ecol Prog Ser 316:239-246

> Halpin PN, Read AJ, Fujioka E, Best BD and others (2009) OBIS-SEAMAP: The world data center for marine mammal, sea bird and sea turtle distributions. Oceanography 22:104-115

Harris PT, Macmillan-Lawler M, Rupp J, Baker EK (2014) Geomorphology of the oceans. Mar Geol 352:4-24

Hazen EL, Jorgensen SJ, Rykaczewski R, Bograd SJ and others (2012) Predicted habitat shifts of Pacific top predators in a changing climate. Nat Clim Change 3:234-238

Hooker SK, Cañadas A, Hyrenbach KD, Corrigan C, Polovina JJ, Reeves RR (2011) Making protected area networks effective for marine top predators. Endang Species Res 13:203-218

> Howell EA, Wabnitz CCC, Dunne JP, Polovina JJ (2013) Climate-induced primary productivity change and fishing impacts on the Central North Pacific ecosystem and Hawaii-based pelagic longline fishery. Clim Change 119:79-93

Hu C, Campbell J (2013) Oceanic chlorophyll-a content. In: Hanes JM (ed) Biophysical applications of satellite remote sensing. Springer-Verlag, New York, NY p 171-203

Hyrenbach KD, Forney KA, Dayton PK (2000) Marine pro- tected areas and ocean basin management. Aquat Conserv: Mar Freshw Ecosyst 10:437-458

Kai ET, Rossi V, Sudre J, Weimerskirch H and others (2009) Top marine predators track Lagrangian coherent structures. Proc Natl Acad Sci USA 106:8245-8250

Kappes M, Shaffer S, Tremblay Y, Foley DG and others (2010) Hawaiian albatrosses track interannual variability of marine habitats in the north pacific. Prog Oceanogr 86: 246-260

Kittinger JN, Koehn JZ, Le Cornu E, Ban NC and others (2014) A practical approach for putting people in ecosystem-based ocean planning. Front Ecol Environ 12: 448-456

- Klain SC, Chan K (2012) Navigating coastal values: participatory mapping of ecosystem services for spatial planning. Ecol Econ 82:104-113

$>$ Klein CJ, Chan A, Kircher Lcundiff AJ and others (2008) Striking a balance between biodiversity conservation and socioeconomic viability in the design of marine protected areas. Conserv Biol 22:691-700

Knight AT, Cowling RM, Difford M, Campbell BM (2010) Mapping human and social dimensions of conservation opportunity for the scheduling of conservation action on private land. Conserv Biol 24:1348-1358

Koehn JZ, Reineman DR, Kittinger JN (2013) Progress and promise in spatial human dimensions research for ecosystem based ocean planning. Mar Policy 42:31-38

- Kot CY, Fujioka E, Hazen LJ, Best BD, Read AJ, Halpin PN (2010) Spatio-temporal gap analysis of OBIS-SEAMAP projectdata: assessment and way forward. PLoS ONE 5: e12990

> Le Cornu E, Kittinger JN, Koehn JZ, Finkbeiner EM, Crowder LB (2014) Current practice and future prospects for social data in coastal and ocean planning. Conserv Biol 28:902-911

Le Traon PY, Larnicol G, Guinehut S, Pouliquen S and others (2009) Data assembly and processing for operational oceanography: 10 years of achievements. Oceanography 22:56-69

> Levin SA (1994) Patchiness in marine and terrestrial systems - from individuals to populations. Philos Trans R Soc Lond B Biol Sci 343:99-103

> Levy JM, Snowden D, Clark C, Crane K and others (2011) The global ocean observing component of IOOS: implementation of the initial global ocean observing system for climate and the path forward. Mar Technol Soc J 45:9-18

Lourie SA, Vincent ACJ (2004) Using biogeography to help set priorities in marine conservation. Conserv Biol 18: 1004-1020

> Maritorena S, Hembise Fanton d'Andon O, Mangin A, Siegel DA (2010) Merged satellite ocean color data products using a bio-optical model: characteristics, benefits and issues. Remote Sens Environ 114:1791-1804

- Martin M, Dash P, Ignatov A, Banzon V and others (2012) Group for high resolution sea surface temperature (GHRSST) analysis fields inter-comparisons. Part 1: a GHRSST multi-product ensemble (GMPE). Deep-Sea Res II 77-80:21-30

Maxwell SM, Hazen EL, Bograd SJ, Halpern BS and others (2013) Cumulative human impacts on marine predators. Nat Commun 4, article no. 2688, doi:10.1038/ncomms 3688

> Maxwell SM, Ban N, Morgan LE (2014) Pragmatic approaches for effective pelagic marine protected area management. Endang Species Res 26:59-74 
Maxwell SM, Hazen EL, Lewison RL, Dunn DC and others (2015) Dynamic ocean management: defining and conceptualizing real-time management of the ocean. Mar Policy 58:42-50

> Metzger EJ, Smedstad OM, Thoppil PG, Hurlburt HE and others (2014) US Navy operational global ocean and Arctic ice prediction systems. Oceanography 27:32-43

- Michael PE, Jahnecke J, Hyrenbach KD (2014) Relative influence of static and dynamic features on black-footed albatross (Phoebastria nigripes) habitat use in central California Sanctuaries. Fish Oceanogr 23:18-31

Naidoo R, Balmford A, Ferraro PJ, Polasky S, Ricketts TH, Rouget M (2006) Integrating economic costs into conservation planning. Trends Ecol Evol 21:681-687

O'Dor R, Boustany AM, Chittenden CM, Costello MJ and others (2012) A census of fishes and everything they eat: how the census of marine life advanced fisheries science. Fisheries 37:398-409

Palacios D, Bograd S, Foley D, Schwing F (2006) Oceanographic characteristics of biological hot spots in the north pacific: a remote sensing perspective. Deep-Sea Res II 53:250-269

> Pereira JJ, Schultz ET, Auster PJ (2014) Geospatial analysis of habitat use by silver hake Merluccius bilinearis in the Gulf of Maine. Endang Species Res 23:219-227

Pikesley SK, Maxwell SM, Pendoley K, Costa DP and others (2013) On the front line: integrated habitat mapping for olive ridley sea turtles in the southeast Atlantic. Divers Distrib 19:1518-1530

Pinsky ML, Worm B, Fogarty MJ, Sarmiento JL, Levin SA (2013) Marine taxa track local climate velocities. Science 341:1239-1242

Pittman SJ, Connor DW, Radke L, Wright DJ (2011) Application of estuarine and coastal classifications in marine spatial management. In: Wolanski E, McLusky DS (eds) Treatise on estuarine and coastal science, Vol 1. Academic Press, Waltham, p 163-205

> Ready J, Kaschner K, South AB, Eastwood PD and others (2010) Predicting the distributions of marine organisms at the global scale. Ecol Model 221:467-478

- Richardson EA, Kaiser MJ, Edwards-Jones G, Possingham HP (2006) Sensitivity of marine-reserve design to the spatial resolution of socioeconomic data. Conserv Biol 20: 1191-1202

Richmond A, Kaufmann RK, Myneni RB (2007) Valuing ecosystem services: a shadow price for net primary production. Ecol Econ 64:454-462

Roberts JJ, Best BD, Dunn DC, Treml EA, Halpin PN (2010) Marine geospatial ecology tools: an integrated framework for ecological geoprocessing with ArcGIS, Python, R, MATLAB, and C++. Environ Model Softw 25: 1197-1207

Roemmich D, Johnson GC, Riser S, Davis R and others (2009) The Argo program: observing the global ocean with profiling floats. Oceanography 22:34-43

Rudnick DL (2016) Ocean research enabled by underwater gliders. Annu Rev Mar Sci 8:519-541

Shaffer SA, Costa DP (2006) A database for the study of marine mammal behavior: gap analysis, data standarization and future directions. IEEE J Oceanic Eng $31: 82-86$

Editorial responsibility: Brendan Godley, University of Exeter, Cornwall Campus, UK
Sloan NA (2002) History and application of the wilderness concept in marine conservation. Conserv Biol 16:294-305

St. Martin K (2001) Making space for community resource management in fisheries. Ann Assoc Am Geogr 91: 122-142

Stephenson SL, Mascia MB (2009) Putting people on the map: an approach to integrating social data in conservation planning. SSWG Working Paper 1. Society for Conservation Biology, Social Science Working Group Washington, DC

Suryan RM, Sato F, Balogh GR, Hyrenbach KD, Sievert PR, Ozaki K (2006) Foraging destinations and marine habitat use of short-tailed albatrosses: a multi-scale approach using first-passage time analysis. Deep-Sea Res II 53: 370-386

Suryan RM, Santora JA, Sydeman WJ (2012) New approach for using remotely sensed chlorophyll a to identify seabird hotspots. Mar Ecol Prog Ser 451:213-225

Tang ZY, Wang ZH, Zheng CY, Fang JY (2006) Biodiversity in China's mountains. Front Ecol Environ 4:347-352

Toonen RJ, Wilhelm TA, Maxwell SM, Wagner D and others (2013) One size does not fit all: the emerging frontier in large-scale marine conservation. Mar Pollut Bull 77:7-10

Trebilco R, Halpern BS, Flemming JM, Field C, Blanchard W, Worm B (2011) Mapping species richness and human impact drivers to inform global pelagic conservation prioritization. Biol Conserv 144:1758-1766

> Treml EA, Roberts J, Chao Y, Halpin PN, Possingham HP, Riginos C (2012) Reproductive output and duration of the pelagic larval stage determine seascape-wide connectivity of marine populations. Integr Comp Biol 52:525-537

> Vandepitte L, Hernandez F, Claus S, Vanhoorne B and others (2011) Analysing the content of the European ocean biogeographic information system (EurOBIS): available data, limitations, prospects and a look at the future. Hydrobiologia 667:1-14

- Webb TJ, Vanden Berghe E, O'Dor R (2010) Biodiversity's big wet secret: the global distribution of marine biological records reveals chronic under-exploration of the deep pelagic ocean. PLoS ONE 5:e10223

White C, Halpern BS, Kappel CV (2012) Ecosystem service tradeoff analysis reveals the value of marine spatial planning for multiple ocean uses. Proc Natl Acad Sci USA 109:4696-4701

Williams R, Grand J, Hooker SK, Buckland ST and others (2014) Prioritizing global marine mammal habitats using density maps in place of range maps. Ecography 37 : 212-220

Wingfield DK, Peckham SH, Foley DG, Palacios DM and others (2011) The making of a productivity hotspot in the coastal ocean. PLoS ONE 6:e27874

Woodworth PL, Menéndez M (2015) Changes in the mesoscale variability and in extreme sea levels over two decades as observed by satellite altimetry. J Geophys Res 120:64-77

Yesson C, Clark MR, Taylor ML, Rogers AD (2011) The global distribution of seamounts based on 30 arc seconds bathymetry data. Deep-Sea Res I 58:442-453

Zhang HM, Bates JJ, Reynolds RW (2006) Assessment of composite global sampling: sea surface wind speed. Geophys Res Lett 33:L17114, doi:10.1029/2006GL027086

Submitted: June 1, 2015; Accepted: November 28, 2015

Proofs received from author(s): January 30, 2016 